\title{
Paediatric Nephrology: Scientific Study of Kidneys and their Diseases in Infants and Children*
}

\author{
HENRY L. BARNETT \\ From the Department of Pediatrics, Albert Einstein College of Medicine, \\ and the Bronx Municipal Hospital Center, New York, U.S.A.
}

The first George Frederic Still Memorial Lecture was delivered in 1943 by S. P. Bedson, Professor of Bacteriology at the London Hospital. In expressing his appreciation for being asked to inaugurate this lectureship, he described his particular satisfaction that the choice should have fallen on a laboratory worker since it carried with it the assurance that research of the kind he had been doing, despite its academic flavour, was not without appeal to those engaged in clinical medicine. It may be a measure of one of the changes that has occurred in academic medicine in the intervening 22 years that with equal fervour I must express my satisfaction that the choice for the lecture this year has fallen on a paediatrician and clinical investigator, who is reassured that research of the type he has been doing, despite its clinical flavour, is still not without appeal. My aim, in fact, in this lecture will be to attempt to demonstrate how a primary and continuing interest in paediatrics served as the stimulus for a series of investigations of developmental renal physiology and of renal disease in infants and children.

First of all, however, I should like to express my own deep appreciation to the British Paediatric Association for having asked me to give the 12th George Frederic Still Memorial Lecture. In one of the series of Pediatric Profiles in the Journal of Pediatrics, Sir Wilfred Sheldon (1956) described Still's major role in the establishment of paediatrics as a separate field of inquiry and practice in this country. Perhaps some of the differences between both academic paediatrics and paediatric practice in our two countries can be explained by the fact that a comparable pioneering effort had been made some 35 years earlier in the United States by Abraham

\footnotetext{
* The George Frederic Still Memorial Lecture, delivered at the Annual Meeting of the British Paediatric Association in Scarborough, April 22, 1965.
}

Jacobi $\dagger$. How comforting to realize that in one respect our history is older than yours. Still's published work, like Jacobi's, dealt for the most part with clinical, curative medicine, representing, as pointed out by Professor Crewe (1955), interests entirely in accord with the stage of development of paediatrics and with the needs of that time. This solid, clinical foundation was necessary for and permitted the emergence of the next major phase of paediatrics in which physiological and biochemical explanations were sought in an attempt to understand the mechanisms of development and of disease. The early contributors to this subsequent phase of paediatrics could be considered successors to Still, and I should like to take this opportunity to acknowledge the outstanding contributions of one of them, Professor Alexis F. Hartmann, Sr., who died last September. Professor Hartmann was a corresponding member of this association. Your President, Professor Gaisford, and I were both students of his, and with many others throughout the world remember him with warm affection and deep respect.

My subject today concerns infants, children, and their kidneys.

There may be some who will challenge my espousing the cause of paediatric nephrology by making it the subject of this lecture. If so, I must admit that the decision to do so was made with some reluctance. Our ambivalence about the use of this and similar paediatrically diversive terms reflects our uneasiness about the developments of more and more specialization within paediatrics. On the one hand we seek to preserve the concept of the unity of the child and to understand his interrelationships with his family and with society. On the other, the

t In 1906 Still became the first Professor of the Diseases of Children in the United Kingdom at King's College. Jacobi had been appointed Clinical Professor of Diseases of Children at the College of Physicians and Surgeons of Columbia University in 1870. 
complexities of paediatric cardiology, neurology, haematology - and nephrology, among others-have become so great that productive research, mechanized teaching, and optimal clinical care of the speciality's complicated patients all require everincreasing specialization. Acceptance of paediatric nephrology acknowledges the scientific necessity for such specialization and, indeed, welcomes the advances which have made it necessary. Its effect on general paediatrics is a very important but separate matter.

My purpose here then, in a sense, will be to present the case for paediatric nephrology, not as an isolated speciality, but one that, with others, must bring its specialized knowledge to general paediatrics and bridge it with both foetal and adult medicine. My evidence will consist of investigations of developmental renal physiology and its relevance, and of observations on infants and children with renal disease. Examples will be drawn for the most part from work done together with Dr. Chester $M$. Edelmann, Jr., and our associates in the paediatric renal and electrolyte research unit of the Albert Einstein College of Medicine and in the paediatric renal clinics of the Bronx Municipal Hospital Center.

\section{Developmental Renal Physiology and its Relevance}

A large share of our knowledge of developmental renal physiology rests upon the work of a member of this association, Professor R. A. McCance. From his work with Widdowson and their associates, from some of our own work, and from that of many others, it is now possible to describe in some detail the functional status of the kidney in newborn infants and its postnatal development. It has been known since 1940 (Barnett) that glomerular filtration rate in young infants is low relative to a number surface area, volume of extracellular fluid, and rates of consumption of oxygen, calories, and fluid. It has been shown also that the relation between glomerular filtration rate and many tubular functions change as the infant matures. Although a great of structures and functions of the body including

deal has been written about these changing relations, referred to loosely as renal immaturity, it is doubtful whether their true developmental significance is understood. However, something is known about their consequences, many of which are of major clinical importance.

Drug dosage and drug poisoning in infants. Enthusiasm for the enormous benefits gained from the discovery of many new classes of effective drugs has been tempered by an increasing concern about drug reactions, many of which have been unexpected and some desperately serious. Increasing knowledge of their mechanism of action promises the development of an even greater number of drugs in the future with an accompanying increase in adverse reactions. As paediatricians we must continuously be concerned with and responsible for assessing the sometimes narrow balance between the benefits and dangers of drugs used in infants and children and be aware also of the potential danger to the foetus of drugs given to pregnant women. An important aspect of this subject of developmental pharmacology concerns renal handling of drugs in young infants. As an example (Table), the clearance of penicillin $G$ in premature infants (Barnett, McNamara, Shultz, and Tompsett, 1949) is about $90 \mathrm{ml} . / 1 \cdot 73 \mathrm{sq}$. $\mathrm{m}$. compared with a value of $560 \mathrm{ml}$. in children. If rates of absorption and metabolism and the volume of distribution were the same in the two groups, a dose of penicillin given on the basis of surface area should, at equilibrium, produce concentrations in blood about 6 times as high in infants as in children. The larger volume of distribution associated with the proportionately larger volume of extracellular fluid in young infants would lower this value by a factor of 1.5 to 2 . A slower rate of absorption would lower the concentration further but would maintain it longer. Now it happens that in most circumstances high and prolonged concentrations of penicillin in blood are desirable. With drugs of greater toxicity, however, unexpectedly high concentrations in body fluids may be dangerous. In anticipating from a given dose

TABLE

Renal Clearances of Inulin and Penicillin $G$ in Premature Infants and Children

\begin{tabular}{|c|c|c|c|c|c|}
\hline \multirow{2}{*}{ No. } & \multirow{2}{*}{ Age } & \multirow{2}{*}{ Weight (kg.) } & \multirow{2}{*}{ Height (cm.) } & \multicolumn{2}{|c|}{ Mean Clearances (ml./min./1.73 sq. m.) } \\
\hline & & & & Inulin & Penicillin G \\
\hline 12 & $3-12$ yr. & $13-46$ & Iren $95-150$ & $\begin{array}{c}127 \\
(93-145)\end{array}$ & $\begin{array}{c}560 \\
(311-954)\end{array}$ \\
\hline 4 & 4-8 dy. & $2 \cdot 2-2 \cdot 3$ & $\begin{array}{l}\text { Infants } \\
47-47 \cdot 5\end{array}$ & $\begin{array}{c}44 \\
(31-53)\end{array}$ & $\begin{array}{c}90 \\
(72-114)\end{array}$ \\
\hline
\end{tabular}


what the concentration in body fluids of a drug will be, it is important to consider the developmental fact that the renal handling of the drug may be different in young infants; and that in most if not all instances the rate of renal excretion will be decreased.

Altered renal function in the young infant may assume even greater importance in accidental drug poisoning, another increasingly serious paediatric problem. A tragic example of this was the hospital disaster involving mass accidental salt poisoning in infancy, reported in 1963 by Finberg, Kiley, and Luttrell. Owing to an error, sodium chloride was used in place of cane sugar in the preparation of formulae which subsequently were estimated to contain approximately $1,000 \mathrm{mEq}$ sodium/litre. 14 infants, 12 of whom were newborns and 2 less than 3 months, received one or more of these salt feedings: 6 of the 14 died, the first 5 before the nature of the problem was realized. The highest concentrations of sodium in serum ranged from 162 to $274 \mathrm{mEq} / \mathrm{l}$. in the 8 infants in whom it was measured. 4 of the infants were treated by peritoneal dialysis; in 2 of these it was believed that survival would have been unlikely without it.

For several obvious reasons it is not possible to compare these experiences with what might have happened to older children had they received equivalent excesses of salt; it is not even possible to say what would constitute equivalent doses. Both from clinical experience and from what we do know about developmental renal physiology, however, we can be fairly certain that the results would have been different and far less disastrous. Developmental differences in other physiological functions, especially of the cardiopulmonary and neurocirculatory systems, may make newborn infants more susceptible than older children to the harmful effects of this type of salt poisoning. Nevertheless, these observations do serve to demonstrate that the stage of development of renal function in young infants, so adequate under normal circumstances, may impose a serious handicap under the types of stresses imposed by drug poisoning. It would not conflict with developmental concepts if it turned out that physiological functions, harmoniously organized to help the young infant to grow and develop, might, under abnormal environmental conditions, create imbalances and impose handicaps.

Fluid and electrolyte therapy and infant feeding. Observations on the development of renal function in young infants, especially concentrating mechanisms, have provided an important part of the physiological basis for clinical practices involving both fluid and electrolyte therapy and certain aspects

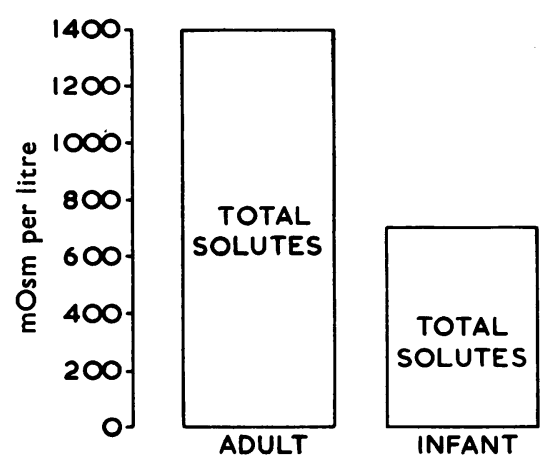

FIG. 1.-Renal concentrating capacity in infants and adults. Although measurements indicate that the mean value for maximum total osmolarity in adults is actually between 1,100 and 1,200 mOsm./l. and that the low value for infants is due to a low rate of excretion of urea, the familiar (though inaccurate) values of 1,400 and 700 are used here for the sake of the argument being developed.

of infant feeding. It was shown several years ago (Fig. 1) that when infants were deprived of water for a period of 12 to 14 or 16 hours, the concentration of osmotically active solutes in the urine increased to a maximum of about $700 \mathrm{mOsm}$./1. in striking contrast to values as high as 1,400 achieved by adults under similar circumstances. This relatively simple physiological observation, suggesting that young infants have difficulty concentrating solutes in the urine, was applied to a variety of clinical situations. Many of these applications, as well as the interpretation of the original observation, are now known to be incorrect.

Physiologically, the observation was interpreted as indicating either decreased elaboration or release of antidiuretic hormone, or decreased responsiveness of the renal tubules of the young infant. Its relevance to parenteral fluid therapy was based on the calculation that at a maximum urinary osmolality of $1,400 \mathrm{mOsm}$./1., the minimum volume of water in which $1 \mathrm{mOsm}$. of any urinary solute could be excreted would be $0.7 \mathrm{ml}$. At a maximum concentration of only $700 \mathrm{mOsm}$./1. this value would be doubled, $1.4 \mathrm{ml}$. of water being required for the excretion of $1 \mathrm{mOsm}$. solute. It was argued, therefore, that under clinical circumstances where solutes needed to be excreted but water conserved, as in the infants with salt poisoning, the young infant, requiring more urinary water to excrete excess solute, would be at a disadvantage. Taken together with other aspects of water and solute physiology, these considerations suggested the advisability of using hypotonic solutions containing 100 to $200 \mathrm{mOsm}$./1. instead of isotonic saline in 


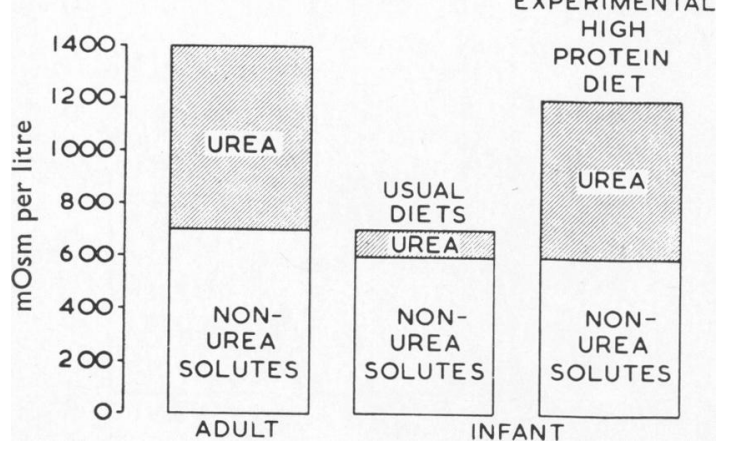

FIG. 2.-Renal concentrating capacity in infants and adults, taking into account the effects of dietary protein intake on urinary concentration of urea and other solutes.

parenteral fluid therapy. Finally, the observation was applied to infant feeding practices. Since diets with a higher protein content result in higher rates of excretion of urinary solutes, it was assumed that infants on such diets would have higher renal water requirements and be more susceptible to dehydration during thirsting than infants receiving lower protein diets.

These interpretations and applications all seemed very reasonable until it was realized that none of them had taken into account the nature of the solute requiring excretion and the unique handling by the kidneys of the largest single component, urea.

From observations made over 30 years ago by Gamble, McKhann, Butler, and Tuthill (1934), it could have been anticipated that during thirsting increased excretion of urea, unlike other solutes, would require little or no additional urinary water. When their studies were recalled a few years ago and the nature of the solute in concentrated urine was examined, it was found, as shown in Fig. 2, that whereas in adults about one-half of urinary solute is urea, in infants the urine contains relatively little urea. Extraordinarily high amounts of protein must be given to young infants to raise their rate of excretion of urea to the adult level; however, under these circumstances, since urea binds relatively little urinary water, it brings the concentration of total solutes very close to the maximum value observed in adults (Edelmann, Barnett, and Troupkou, 1960). The lower value for total osmolality in young infants is to be explained, therefore, not primarily on the basis of renal immaturity but almost entirely by the metabolic fact that on all ordinary diets infants store most of the protein they ingest and excrete very little urea.

How does this new knowledge affect previous interpretations and applications? Physiologically, it seems almost certain now that any lower capacity the infant might have for concentrating solutes in the urine is due not to lack of action of antidiuretic hormone but rather to differences in the mechanisms concerned with the production and maintenance of a high interstitial osmolality in the renal medulla (Edelmann and Barnett, 1960). In addition to active sodium transport, these mechanisms include the loops of Henle functioning efficiently as countercurrent multipliers and the vasa rectae as countercurrent exchangers. It is known that maximum interstitial concentration gradients are related directly to the lengths of the loops of Henle, which almost certainly are shorter in young infants (Peter, 1927). Additional work will be required, however, before the developmental aspects of these particular renal functions are understood.

The situation in respect to parenteral fluid therapy remains unchanged, since the calculation of the minimum volume of water needed by infants to excrete one mOsm. urinary solute was based correctly, though unknowingly, almost entirely on nonurea solutes. On the other hand, since renal water requirements are determined mainly by the rate of excretion of non-urea solutes, which are concentrated by older children and adults also only to a maximum of about $700 \mathrm{mOsm}$./1., it should be pointed out that arguments for the use of hypotonic intravenous solutions apply equally well to them.

Application of these physiological principles to infant feeding practices required considerable revision. Contrary to previous assumptions, the protein content of the diet has little effect either on water conservation or on resistance to dehydration during episodes of complete thirsting such as may occur during acute infections in young infants (Edelmann and Barnett, 1960). Under circumstances simulating the type of large extrarenal losses of hypotonic fluid that may occur during acute diarrhoea, the water content of the diet must be reduced to about $30 \%$ of control values before the composition of the diet exerts any differential effects on water balance (Drescher, Barnett, and Troupkou, 1962). Finally, with all diets used commonly in practice, renal water requirements are determined mainly by the rate of excretion of nonurea solutes, which are increased only slightly by a higher protein diet. Contrary to earlier conclusions, therefore, the protein content of the diet has very little effect on minimal renal water requirements.

Repeated instances of this sort where we have had to modify or change completely our earlier conclusions should serve to demonstrate that a great deal remains to be learned about the relevance of developmental renal and electrolyte physiology. 
Renal Diseases in Infants and Children

Recent advances in the understanding of many renal diseases in infants and children can be traced, as happens so often, to the development of new techniques. A safe procedure for performing percutaneous renal biopsy is providing important new correlations between morphological, histochemical, and immunochemical properties of the kidney on the one hand, and physiological functions and clinical manifestations on the other. As a result of such investigations, it is imperative that our concepts concerning almost every aspect of renal disease in infants and children be re-examined, a truly agonizing process in a field of such historic medical contributions and yet one so riddled with speculation.

Although the study of renal biopsies is yielding important new information about post-streptococcal acute glomerulonephritis, the most recent stimulus for re-examining our concepts has arisen from another source. From experience with adult patients, many physicians interpret the natural history of post-streptococcal acute nephritis as shown in Fig. 3. Since most adults with chronic nephritis give no history of previous renal disease, it is assumed, with no real evidence, that their disease began with an unrecognized attack of acute nephritis during childhood. It is known from systematic studies of the urine of children recovering from streptococcal infections, that as high as $95 \%$ of children with acute nephritis may be unrecognized clinically. The course of the disease in those children in whom it is recognized clinically and who survive the extremely dangerous early complications, is, as shown in Fig. 4. According to this interpretation there is no connexion at all between post-streptococcal acute nephritis in children and chronic nephritis in adults. Complete and permanent recovery is shown to be virtually certain in children surviving the early complications. Less than $1 \%$ of children with acute nephritis are indicated as progressing to chronic nephritis, and in those cases progressive disease evolves directly from the acute attack, rather than following a prolonged asymptomatic latent period, as postulated without evidence in the first interpretation.

There is some evidence in support of this second interpretation. Follow-up studies of children known to have had acute nephritis have not disclosed significant numbers of patients developing asymptomatic latent nephritis (Hebert, 1952). Such studies, of course, do not answer the more difficult question of whether chronic nephritis in adults is a result of unrecognized acute nephritis in children. Since the recovery rate is so complete

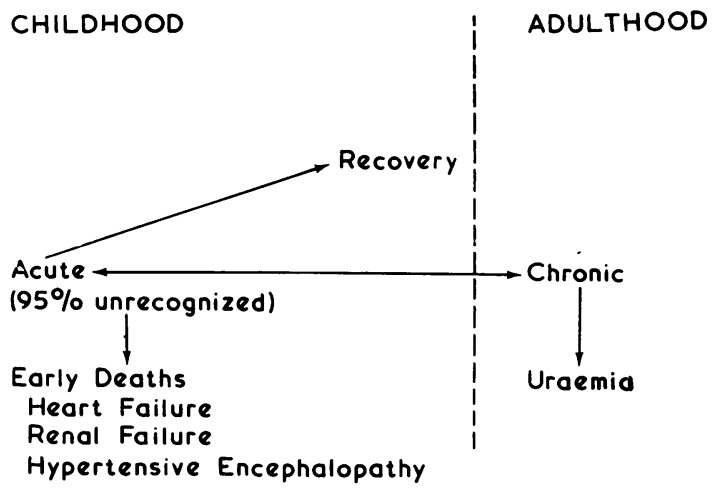

FIG. 3.-Natural history of acute glomerulonephritis in children as interpreted by many physicians.

among children whose symptoms permit recognition of the disease, however, it seems unlikely that latent and chronic nephritis would occur more frequently in children whose initial disease clinically was so mild that it remained unrecognized. In addition, a cross-sectional survey of the prevalence of abnormal Addis counts among apparently healthy 12-year-old boys (Schlesinger, Overton, and Chase, 1956) failed to reveal a prevalence rate of latent nephritis which would be required if, in fact, it constituted the major source of chronic nephritis in adults. Much more information is required to provide a final answer to this difficult but important question of the natural history of acute nephritis in children, and it could be obtained by proper epidemiological methods. Present evidence, however, does support the view held by most paediatric nephrologists.

Why do we harp so strongly upon these interpretations of the natural history of nephritis in children? The reason is that they must provide the principles upon which some of our most important practices

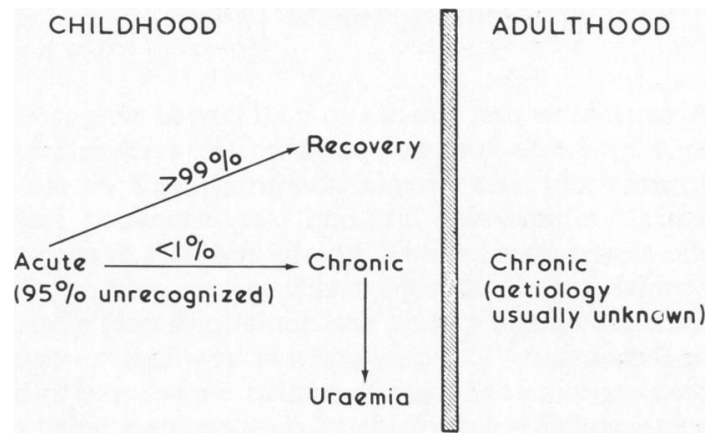

FIG. 4.-Natural history of acute glomerulonephritis in children as interpreted by most paediatric nephrologists. 
are based. In addition to the early recognition and prompt treatment of the early complications of heart failure, hypertensive encephalopathy, and acute renal failure, the single most important aspect of our care of a child with acute nephritis is what we say to the parents and, when appropriate, to the child about prognosis. The interpretation of the natural history of the disease determines whether, after the initial stage, one says: 'Your child will probably recover, but even if he appears to he may develop chronic nephritis many years later', or, 'your child will almost certainly recover and once he does he will be completely well and as unlikely to have renal disease later in life as if he had never had nephritis. He may, in fact, have gained some degree of immunity against the rare possibility of a subsequent attack.' One need not be a parent of a child with nephritis to appreciate the difference between these two statements.

Advice on other important aspects of care is also determined by the interpretation of the natural history of acute nephritis. There are a number of examinations by which the progress of recovery of a child with acute nephritis can be judged. Some of these are shown diagrammatically in Fig. 5.

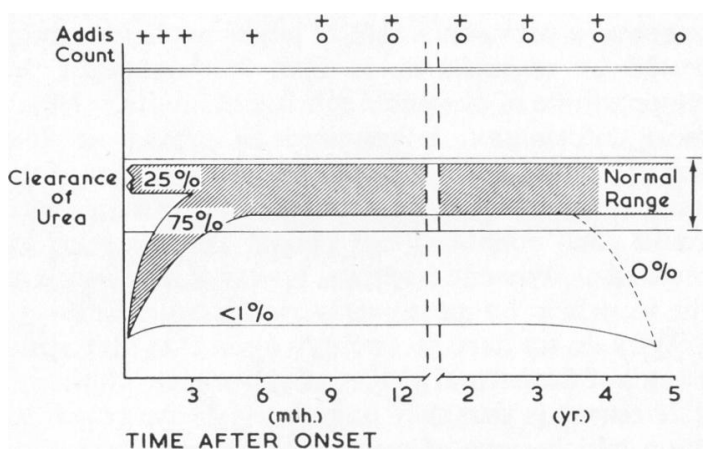

FIG. 5.-Laboratory data during the course of acute glomerulonephritis in children.

Abnormal urines, which can be followed adequately only by Addis counts, persist on the average for 6 months and may remain abnormal for 2 or more years. Glomerular filtration rate, estimated from the clearance of urea, if initially reduced returns to normal usually within a week or two, occasionally not until after a month, and sometimes only after 2 or 3 months. The only patients in whom we have seen chronic nephritis follow what we believed to be acute nephritis were those whose clearances failed to return to normal after the initial episode (Fig. 5). If the clearances have remained normal or have returned to normal during the first few weeks, we are entirely confident that recovery will occur and advise that usual activity need no longer be restricted. This recommendation is in sharp contrast again with the practices of physicians who, believing chronic nephritis may follow a prolonged latent period manifested only by an abnormal urine, and assuming that restricted activity may prevent the development of chronic nephritis, advise prolonged bed-rest. If such restricted activity for periods of months or even years during middle childhood is unnecessary, as we believe it is, children must not be subjected to its almost immeasurably harmful effects.

Until recently we were relatively satisfied with our clinical care of children, despite the unanswered questions concerning aetiology, and most related research was directed toward the aetiological role of the $\beta$-haemolytic streptococcus and the possibility of prevention. Our experience during the past five years, however, has disturbed our clinical confidence, not in treating or assessing the prognosis in children with post-streptococcal acute nephritis, but in establishing the diagnosis itself.

Because, in our experience, the development in children of chronic nephritis following acute nephritis was so rare, we became concerned when we realized that out of 42 children admitted consecutively to our service with the diagnosis of acute nephritis, 3 had failed to recover as we had expected. One of

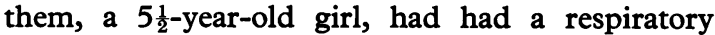
infection four weeks before admission, followed in one week by gross haematuria and oedema. On admission her blood pressure was $150 / 90 \mathrm{~mm}$. Hg. Urinalysis revealed 4-plus proteinuria and innumerable red blood cells. Her blood urea nitrogen was $41 \mathrm{mg} . / 100 \mathrm{ml}$., and her antistreptolysin-0 titre, 1,250 units. She was oliguric for two weeks but improved gradually. Her urea clearance, however, rose only to the range of $60-70 \%$. Although she appeared clinically well during the following year, her inulin clearance at the end of it was only 15 to $20 \mathrm{ml}$. per minute. Recurrence of gross haematuria and oedema three weeks after what appeared to be a typical onset of acute nephritis did attract our attention when she entered hospital, but we have seen this often enough in children who have recovered that even in retrospect we would have accepted the diagnosis. The specimen obtained by percutaneous renal biopsy on the 25th day of illness showed severe glomerulonephritis with glomerular scarring. From her clinical course and from a biopsy done a year later, which showed severe and advanced hyalinization of almost all glomeruli, we had to conclude that she had severe and irreversible renal insufficiency. The clinical course and biopsy 
findings in the other two children were similar (Edelmann, Greifer, and Barnett, 1964).

What is the significance of these recent experiences with children who fail to recover from what clinically appears to be acute nephritis ? It is only recently that we have collected data systematically on children with acute nephritis, and so we have only an impression that there may be an increased frequency in the incidence of severe kidney disease. This impression, however, is shared by other workers in the United States as well as in other countries, and even the possibility of an increase in the incidence demands investigation. An important question is whether on the basis of this recent and relatively small experience we need to alter our views about the prognosis in acute nephritis. I should be very sorry indeed if this occurred as a result of this discussion. In none of these three children did the clearances return to normal after what appeared to be the initial attack. We continue to be quite confident, therefore, that the great majority of children with acute nephritis, whose clearances remain or become normal, have an excellent prognosis. The more troublesome question concerns the nature of the kidney disease in these three children and the possibility that instead of post-streptococcal acute nephritis, they had, in fact, a different and more severe form of renal disease.

Without implying any similarity, it is worth considering here the very disturbing accounts of so-called Balkan nephritis, an endemic form of chronic nephropathy observed in localized areas of Yugoslavia, Rumania, and Bulgaria (Griggs and Hall, 1964). In some villages the prevalence of proteinuria has been found to be as high as $33 \%$, in contrast to the expected figure of less than $1 \%$, and it is estimated that in some districts $25 \%$ of deaths are due to uraemia. Despite extensive epidemiological studies, the aetiology of this serious endemic type of nephropathy remains unknown, the most likely cause being some unidentified toxic factor.

Taken together with our recent experiences, these observations and the increasingly frequent reports of the haemolytic-uraemic syndrome (Gianantonio, Vitacco, Mendilaharzu, Rutty, and Mendilaharzu, 1964) raise again the question of toxicologicallyinduced disease. Children are being exposed to an ever-increasing number of potentially harmful agents, not only iatrogenically but also in the form of food additives, insect sprays, and other environmental poisons. It would not be unexpected for such toxic exposure to result in renal disease, the agents acting either as direct nephrotoxins or as sensitizing factors, singly or as co-determinants in genetically determined individuals. In any event, the warnings justify our serious concern and constant attention.

\section{Some Future Directions of Paediatric Nephrology}

What are some of the advances we can expect during the next few years in paediatric nephrology? Studies of developmental renal physiology and its relevance will focus even more, I believe, on the newborn infant with further attempts to investigate renal function before birth and the effects of prenatal factors on postnatal development (McCance and Widdowson, 1954). We can expect that still more disturbances of specific renal tubular functions will be discovered, and can anticipate greater understanding of the genetic and enzymatic mechanisms involved. One of the unanswered questions is whether some of these congenital renal tubular disorders represent developmental failures or arrests, or even the low range of distribution of normal development, rather than qualitative departures from normal function. Young and Levin (Peonides, Levin, and Young, 1965) and Edelmann are studying developmental aspects of the renal handling of hydrogen ions partly in the attempt to answer this question in various types of renal tubular acidosis.

The application of statistical and epidemiological methods will not only define clinical problems more precisely and assure proper therapeutic assessments, but also by identifying associations, point the way toward new research on mechanisms and aetiology of renal disease. For example, Kass (1960) and others have shown that asymptomatic pyelonephritis is far more common than realized and that it can be recognized only by a careful search for bacteriuria. The recognition and treatment of such infections may serve to prevent not only a major cause of chronic renal disease but even one of the causes of prematurity. Thus, in addition to the obvious clinical implications of these important observations, they raise new and unanticipated questions about mechanisms involved in the initiation of premature onset of labour.

Of great importance also to paediatricians is Kunin's epidemiological study (Kunin, Zacha, and Paquin, 1962) showing a prevalence rate of bacteriuria of $1.2 \%$ in schoolgirls with covert and overt incidence rates of 0.7 and $2.9 \%$ per year, respectively. These observations raise the very practical question of whether current practices are keeping pace with the acquisition of new knowledge. They certainly suggest that screening for bacteriuria should be a routine procedure in paediatric practice and in community school health programmes. If it would be difficult if not impossible to add this 
examination to those being done routinely, the question must be asked whether it should not replace one of the current examinations. Despite lack of success thus far, it can be anticipated that as the importance of detecting bacteriuria becomes widely appreciated, simpler methods for it will be devised. The point is, however, that clinical practices, like concepts of disease, need continuously to be reexamined.

The major unanswered questions concerning the treatment of children with the nephrotic syndrome provide striking examples of both the need for and the neglect of the application of statistical methods. When adrenocortical steroids were first used over 15 years ago, no attempt was made to assess properly their therapeutic value by a controlled trial. Unfortunately, as so often happens, the critical period during which it could have been done ethically was lost. Most paediatricians believe now that, in addition to controlling oedema, these agents have a favourable effect on the underlying renal disease. On the other hand, unlike the rare event in which a drug like penicillin is almost completely effective against certain infections, the value of adrenocortical steroid therapy in children with the nephrotic syndrome is not so unequivocal that its universal use can be accepted without question, especially when due attention is paid to the toxic side-effects. Differences between the major questions being asked in two clinical trials being conducted in this country illustrate these points. There is enough uncertainty about the value of adrenocortical steroids in the treatment of adults with the nephrotic syndrome that the trial being conducted by the Medical Research Council has a control group receiving no steroids. In contrast, the collaborative clinical trial in children being coordinated by members of the Department of Social Medicine at St. Thomas' Hospital and of the Department of Paediatrics at Guy's Hospital can ask only the interesting but less important question of whether one of two steroids given by one of two regimens is more effective. Both trials have the great advantage that the results are being correlated with examination of tissue obtained by percutaneous renal biopsy. It should be of interest to paediatricians that the basic question of whether or not adrenocortical steroids are actually indicated in adults with the nephrotic syndrome is still open and that the answer may depend in part upon the type of glomerular pathology. From present information it would not be ethical to withhold steroids from a group of children with the nephrotic syndrome for the purpose of therapeutic assessment. On the other hand, if additional correlations between the clinical course of the disease in both children and adults with various types of glomerular pathology should permit identification of groups of children who are very likely either to recover without steroids or to fail to respond to such therapy, a controlled therapeutic trial may still be indicated to assess the balance between therapeutic value and toxicity.

A more immediate decision of this type may be at hand. Constantly increasing experimental and clinical evidence supports the hypothesis that immunological mechanisms play a central role in the pathogenesis of the nephrotic syndrome. The recent demonstration by Heymann, Hunter, Hackel, and Cuppage (1962) of an autoimmune renal disease in rats adds important experimental support for this concept. Using immunofluorescent techniques and electronmicroscopy, Vernier and associates (Michael, Drummond, Good, and Vernier, 1964) have shown that some children with the nephrotic syndrome have deposits of $\gamma$ and $\beta-1-c$ globulin on the glomerular basement membrane, and that the presence of these immunoglobulins is usually associated clinically with resistance to adrenocortical steroids. These patients appear to respond to immuno-suppressive agents as have some of our patients who, though responsive to steroids, developed such severe toxic effects that the doses required to suppress their proteinuria could not be continued. We are at the stage in the treatment of this group of patients where we are uncertain about the value of treatment with immunosuppressive agents and where not only is a proper therapeutic trial justified but also failure to do one could almost be considered unethical, as suggested by Sir Austin Bradford Hill (1952) when he said: 'It may sometimes be unethical not to experiment.' Since the number of such patients is small, a collaborative trial with its attendant difficulties would be required. Nevertheless, it can be hoped that the experience of having learned so much less than we should have from the uncontrolled use of adrenocortical steroids in children with the nephrotic syndrome will persuade us not to miss the present critical period during which the value of these therapeutic agents can be assessed properly.

\section{Summary}

To sum up, then, I hope I have demonstrated by example that the scope, complexity, and importance of the problems involved require a speciality of paediatric nephrology. Contrary to the deprecating and erroneous statement that scientific specialization involves knowing more and more about less and less, the paediatric nephrologist must draw upon knowledge from an ever-increasing number of disciplines. 
He must have sound basic paediatric training since his general knowledge of infants and children and of human development is what distinguishes him from others whose major interests are in the kidneys and their diseases. Without paediatric training he could not apply information on the development of renal function in young infants to the problems of fluid and electrolyte therapy, nor would he be likely to understand how the interpretation of the natural history of nephritis in children affects his discussions of prognosis with parents. In addition to paediatrics, he must have extensive training in at least one and some knowledge of many other disciplines, including renal physiology and pathology, immunology, endocrinology, enzymology, genetics, and epidemiology. As a clinical investigator he must serve a 'bridging' role, doing person-oriented research, often in co-operation with pre-clinical scientists, on the one hand, and specialized clinical consultation with general paediatricians or family physicians, on the other.

Increasing specialization of the type I am advocating affects not only paediatric research but also the teaching and practice of paediatrics. Some of the difficult problems raised are important to the whole future of paediatrics. However these are solved, and there are probably several different solutions, I do not believe the cause of paediatrics will be served if, in the process, specialities such as paediatric nephrology cannot flourish.

This lecture was prepared during a sabbatical leave supported in part by a fellowship from the Commonwealth Fund of New York while enjoying the hospitality of the Department of Medical Statistics and Epidemiology of the London School of Hygiene and Tropical Medicine. Some of the investigations referred to were supported by grants from the National Heart Institute, the National Institute of Child Health and Human Development, The Division of Research Facilities and Resources, the Health Research Council of The City of New York, the Kidney Disease Foundation of New York, and the Sylvan League, Inc.

\section{REFERENCES}

Barnett, H. L. (1940). Renal physiology in infants and children: I. Method for estimation of glomerular filtration rate. Proc. Soc. exp. Biol. (N.Y.), 44, 654.
- McNamara, H., Shultz, S., and Tompsett, R. (1949). Renal clearances of sodium penicillin $G$, procaine penicillin $G$, and inulin in infants and children. Pediatrics, 3, 418.

Bedson, S. P. (1943). Some recent virus work and its practical import. Arch. Dis. Childh., 18, 113.

Crewe, F. A. E. (1955). Medicine and social science. ibid., 30, 303.

Drescher, A. N., Barnett, H. L., and Troupkou, V. (1962). Water balance in infants during water deprivation. Amer. f. Dis. Child., 104, 366.

Edelmann, C. M., Jr., and Barnett, H. L. (1960). Role of the kidney in water metabolism in young infants. $\mathcal{F}$. Pediat., 56, 154.

$\longrightarrow$ - and Troupkou, V. (1960). Renal concentrating mechanisms in newborn infants. Effect of dietary protein and water content, role of urea, and responsiveness to antidiuretic hormone. $\mathcal{f}$. clin. Invest., 39, 1062.

- Greifer, I., and Barnett, H. L. (1964). The nature of kidney disease in children who fail to recover from apparent acute glomerulonephritis. F. Pediat., 64, 879.

Finberg, L., Kiley, J., and Luttrell, C. N. (1963). Mass accidental salt poisoning in infancy. F. Amer. med. Ass., 184, 187.

Gamble, J. L., McKhann, C. F., Butler, A. M., and Tuthill, E. (1934). An economy of water in renal function referable to urea. Amer. F. Physiol., 109, 139.

Gianantonio, C., Vitacco, M., Mendilaharzu, F., Rutty, A., and Mendilaharzu, J. (1964). The hemolytic-uremic syndrome. F. Pediat., 64, 478.

Griggs, R. C., and Hall, P. W. (1964). Investigations of chronic endemic nephropathy in Yugoslavia. In Renal Metabolism and Epidemiology of Some Renal Diseases. Proc., 15th Annual Conference on The Kidney, ed. J. Metcoff, p. 312. National Kidney Foundation, New York.

Hebert, H. J. (1952). Acute glomerulonephritis in childhood. A study of the late prognosis of twenty-seven cases. F. Pediat., 40, 549.

Heymann, W., Hunter, J. L. P., Hackel, D. B., and Cuppage, F. (1962). Transfer of experimental auto-immune nephrosis in rats. Proc. Soc. exp. Biol. (N.Y.), 111, 568.

Hill, A. B. (1952). The clinical trial. New Engl. F. Med., 247, 113.

Kass, E. H. (1960). The role of asymptomatic bacteriuria in the pathogenesis of pyelonephritis. In Biology of Pyelonephritis, ed. E. L. Quinn and E. H. Kass, p. 399. Little, Brown, Boston.

Kunin, C. M., Zacha, E., and Paquin, A. J., Jr. (1962). Urinarytract infections in schoolchildren. I. Prevalence of bacteriuria and associated urologic findings. New Engl. F. Med., 266, 1287.

McCance, R. A., and Widdowson, E. M. (1954). The influence of events during the last few days in utero on tissue destruction and renal function in the first two days of independent life. Arch. Dis. Childh., 29, 495.

Michael, A. F., Drummond, K. N., Good, R. A., and Vernier, R. L. (1964). Immunoglobulins: clarification of their significance in renal disease and demonstration of response to immunosuppressive therapy. F. clin. Invest., 43, 1291.

Peonides, A., Levin, B., and Young, W. F. (1965). The renal excretion of hydrogen ions in infants and children. Arch. Dis. Childh., 40, 33.

Peter, K. (1927). Untersuchungen über Bau und Entwicklung der Niere. G. Fischer, Jena.

Schlesinger, E. R., Overton, D. E., and Chase, H. C. (1956). Study of children drinking fluoridated and nonfluoridated water. Quantitative urinary excretion of albumin and formed elements. f. Amer. med. Ass., 160, 21.

Sheldon, W. (1956). Pediatric profiles, George Frederic Still. f. Pediat., 49, 229. 